\title{
Failure Analysis and Damage Detection of Partially Grouted Masonry Walls by Enhancing Deformation Measurement Using DIC
}

\author{
M. Bolhassani ${ }^{1 *}$; A.A. Hamid ${ }^{1}$; S. Rajaram ${ }^{2}$; P.A. Vanniamparambil ${ }^{2}$; I. Bartoli ${ }^{1}$; A. Kontsos ${ }^{2}$
}

\begin{abstract}
This study focuses on the deformability and damaging of ungrouted and fully grouted masonry assemblages and a full-scale partially grouted (PG) reinforced masonry wall made of concrete masonry units (CMU). Traditional point-to-point method using strain gages and fullfield measurement technique using digital image correlation (DIC) were implemented to investigate the damage and deformability of specimens. All the specimens were constructed in compliance with the provisions of the Masonry Standards Joint Committee (MSJC 2013) and tested under displacement controlled loading. The DIC method was used to determine nonuniform strain contours on the masonry assemblages. The method was verified by comparing the strains along the selected directions with traditional strain-gage based displacement transducer (TML model) measurements. After verifying the method, it was used to investigate the state of damage and deformability of the wall. It was concluded that full-field measurements using DIC is promising especially when the test specimens experience inelastic deformation and extensive damage. Quantitative mapping of deformation field until the wall capacity is reached was only possible by using DIC. In addition to monitoring the strains across the gage length, the DIC method provided a full-field quantitative strain map of the test specimens to wall capacity and revealed strain hot-spots associated with the maximum strain at crack locations. Characterizing the deformation mechanism and cracking of the PG reinforced masonry wall was performed by determining strain distribution and recognition of cracks corresponding to the wall capacity and strains in higher than $0.3 \%$.
\end{abstract}

Keywords: Partially grouted reinforced masonry wall; masonry assemblages; deformability; full-field measurement; DIC.

\section{Introduction}

1. Civil, Architectural and Environmental Engineering Department, Drexel University, Philadelphia, PA.

2. Mechanical Engineering \& Mechanics Department, Drexel University, Philadelphia, PA.

${ }^{*}$ Ph.D., Department of Civil Architectural and Environmental Engineering, Drexel University, Philadelphia, PA, mb3238@drexel.edu. 
Masonry bearing wall buildings remain one of the relatively less studied structural systems particularly in the case of partially grouted reinforced masonry walls, a common building system in the eastern United States [1-10]. PG walls are essentially reinforced masonry in which only the reinforced cells are grouted while all cells are grouted in fully grouted (FG) walls. This difference can significantly affect the behavior of such walls.. While most reinforced masonry construction in the West Coast is FG, almost all reinforced masonry structures constructed outside the West Coast, including those in regions of high seismic risk are PG.

Due to the important role of the displacement-based concepts in seismic design, the quantification of deformation capacity needs to be investigated precisely. Deformability is defined as the ratio of ultimate deformation to limit deformation [11]. Ultimate deformation is the displacement capacity without a significant drop in load capacity, typically to $80 \%$. Limit deformation, however, has different definitions; for example, it can be defined as twice the deformation that corresponds to $40 \%$ load capacity [11]. During earthquakes, deformability of a structure is an essential property that influences the seismic performance [12].

Ductility is the ability of structures and materials to undergo large deformations without collapse or significant loss in load capacity [13-15]. Due to their low tensile strength, the ductility of the masonry structures are generally low. Improved deformability of such systems can sustain the inelastic deformation demands of natural excitation meeting the code's provisions. Therefore, there is a need to perform comprehensive studies on the deformation capacity of masonry structures. To this end, the deformation capacity of concrete masonry assemblages and shear wall specimens were evaluated in this study. Because of their heterogeneous and orthotropic nature. masonry structures have a complex mechanical behavior that is difficult to quantify and characterize. This is mainly due to the presence of head and bed joints. This issue becomes even more complex when dealing with PG reinforced concrete masonry structures.

To monitor the reinforced masonry wall deformation, in addition to traditional deformation and strain measurement techniques such as strain gages and linear variable differential transformers (LVDTs), a number of non-destructive tests (NDT) using stereo-imaging and laser interferometry have also been reported [16], and [17]. Additionally, to detect defects or to observe the crack growth, different types of non-destructive methods have been applied using 
ultrasounds, acoustic emission and X-ray computerized tomography [18, 19]. Low measurement accuracy, laborious post-processing and high sensitivity to vibrations caused by the testing machines are listed as some of the challenges of the aforementioned methods.

Digital Image Correlation (DIC) can be an ideal method due to its full-field nature. Additionally, it can cross validate traditional gage devices and other NDT techniques [20]. DIC is an optical method capable of measuring the surface deformation of structural elements [21, 22]. The correlation between the images captured in the DIC is based on the comparison between the undeformed and subsequently deformed recorded images. The method is based on tracking random speckle patterns assigned to the desired surface using the fundamental photogrammetry and digital image processing rules. The random speckle patterns can be performed using different patterning techniques such as spray painting, stenciling, speckle patterning, air brushing, etc. [23, 24]. One of the fundamental assumptions in the DIC is that during deformation of the test specimen, the light intensity field defined as a digital grayscale, remains point-wise unchanged. DIC has been investigated theoretically and experimentally by several researchers. Chu et al. [21] developed a measurement technique by combining deformation theory and digital image correlation method. Luo et al. [26] assembled and used a stereo pair of charge-coupled device cameras to measure three-dimensional surface-displacement on a cantilever beam and a compact-tension fracture specimen. Sutton et al. [27] evaluated the feasibility of determining displacement gradients from measured surface-displacement fields and proposed an improved methodology for both the estimation and elimination of noise. Bruck et al. [28] applied NewtonRaphson technique to determine displacements and displacement gradients. They also reported the accuracy of the displacements and displacement gradients for various subset sizes. Peters et al. [29] developed a computer based stress analysis combining digital image correlation of speckle images with an experimental boundary integral method and demonstrated the method on a plate in uniform tension. Choi and Shah [26] observed non-uniform displacements in the displacement contour maps taken at various loading stages on concrete surface using a full-field DIC measuring system. They also illustrated the crack propagation around aggregate interfaces in their study. The DIC results revealed strain concentrations around the crack tip prior to crack extension and cross-validated the results obtained with other non-destructive methods. Corr et al. [31] used DIC to examine interfacial bonding between carbon fiber reinforced polymers and concrete substrates. They analyzed the bond constitutive laws and studied the fracture behavior 
using these DIC results. Helm et al. [32] developed and successfully tested an improved 3D image correlation system to measure bending and local buckling behavior of clamped circular plates under pressure. They measured the surface profile and full-field displacement under the compressive and tensile loading with micron level accuracy using their equipment. Digital image processing has been also used to measure dynamic displacement of a structure. Choi et al. [33] introduced a dynamic displacement vision system (DDVS) to measure the dynamic displacement of the masonry structure and a two-story steel frame structure under seismic loading. They compared their DDVS displacement measurement with linear variable differential transformer (LVDT) results where the percentage of error was $0.471 \%$. A similar application was performed by Lee and Shinozuka [34] to get real-time displacement of a suspension bridge by means of digital image processing technique. Although several studies have been conducted based on the use of DIC in concrete structures, the application of the DIC method to monitor full-field deformation behavior of PG walls has not been well explored. PG walls are an integrated combination of lightly reinforced concrete frame and masonry infill walls. To this aim, this paper presents an experimental investigation targeting surface displacement contour measurements and damage identification of PG reinforced masonry wall specimen and its assemblages. DIC, as a robust full-field surface deformation measurement technique, was implemented herein to capture full-field information on masonry deformation behavior and failure processes.

\section{Experimental program}

\subsection{Wall's assemblages}

Prisms- Ungrouted and fully grouted prisms were built using regular concrete masonry units (CMU) with three courses high in stack bond. The specimens were tested under axial compression loading. Loading was applied by a 1,556 kN capacity MTS actuator mountedon a stiff steel reacting frame,. Regular CMU with 400x200x200 mm nominal size was used to build the ungrouted prisms, whereas fully grouted prisms were constructed using half CMU (200x200x200 mm) to avoid reaching to the nominal capacity of the actuator. In the case of fully grouted specimens, a high slump grout was used according to ASTM C476 requirements. The masonry grout was consisted of 1.00:2.78:0.74 by weight of cement, sand and water, respectively. The same grout mixture was used for all the fully grouted assemblages and also the grouted cells of the wall. Following ASTM C270, type S Portland cement lime (PCL) mortar 
was used in the construction of all specimens. The proportions by volume of Portland cement, lime and masonry sand were 1:0.5:4.5. The test was performed in compliance with the procedure described in ASTM C1314. As illustrated in Fig. 1, all specimens were capped with gypsum to prepare a smooth surface. TML gages were placed at the backside of the specimens considering a nominal gage length of $407 \mathrm{~mm}$ (see [35] and [36] for more detail). The speckle pattern required for the DIC measurements was applied on the front side of the specimens. Fig. 1a,b show the TML, DIC setup and speckle pattern applied on a pristine ungrouted prism.

Bed-joint shear- Three specimens of both ungrouted and fully grouted bed-joint shear assemblages with two units height were constructed flat-wise using two full CMU at the middle, one at the top, and one at the bottom (see Fig. 1c and d). Two middle units were placed with a half inch gap to form a triplet configuration.. In order to impose pure shear in the mortar joints and induce shear slip failure at the CMU-mortar interfaces, vertical load was applied at the top of the middle CMU . A $407 \mathrm{~mm}$ long gage-line was considered for the fully grouted and ungrouted specimens (see Fig. 1d). The gage length can be assumed between any set of points captured by the DIC images. However, as shown in Fig. 1d, for consistency in the measurements, DIC gage length was considered to be the same as the length of the mounted TML gage on the opposite face.

Diagonal compression- A set of diagonal compression tests was performed on the $1.2 \times 1.2 \mathrm{~m}$ ungrouted and the fully grouted assemblages with three units long and six units high. Assemblages were constructed in a running bond and were subjected to the diagonal compression vertical load through top and bottom steel shoes according to ASTM E519. These specimens were used to determine the diagonal tensile strength of the specimens as demonstrated in Fig. 1e,f.
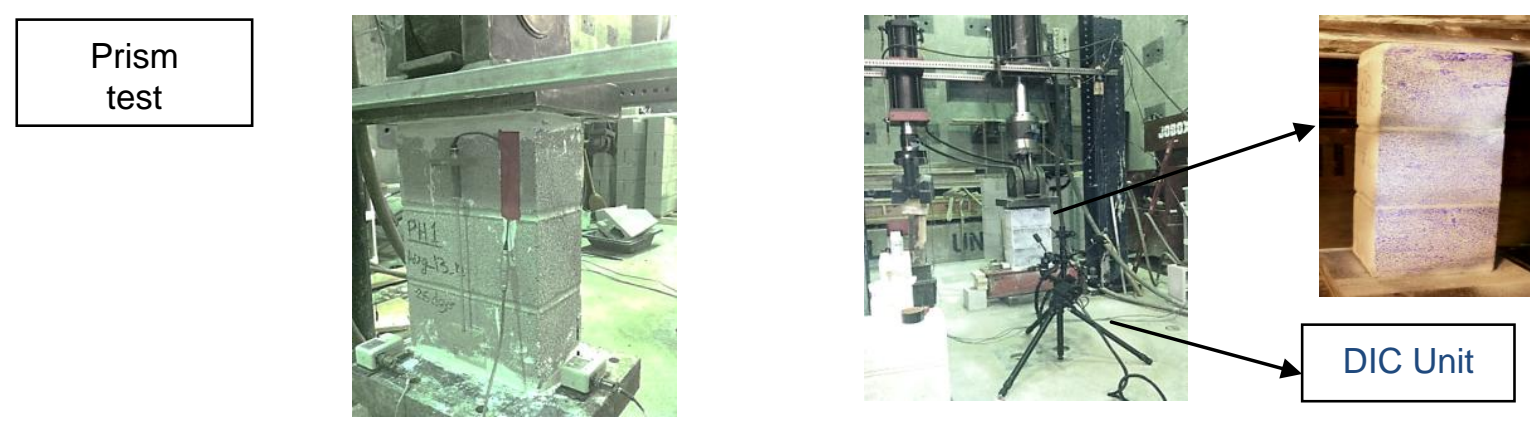
(a) TML measurements (back)

Bed-joint shear test

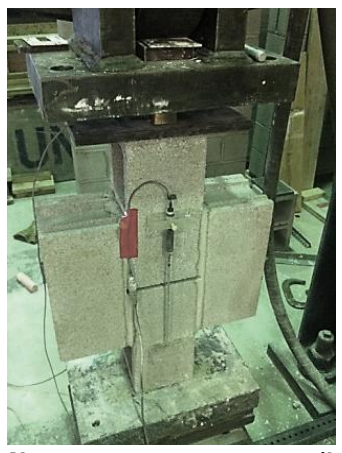

(c) TML measurements (back)

Diagonal compression test

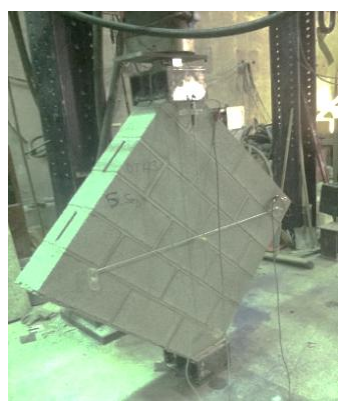

(e) TML measurements (back) (b) DIC measurements (front)

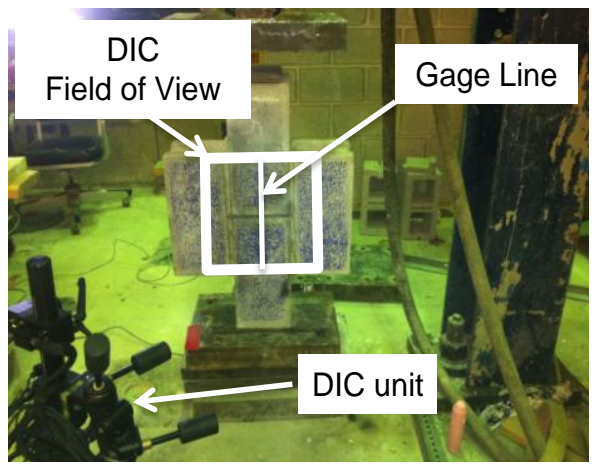

(d) DIC field of view and line gage (front)

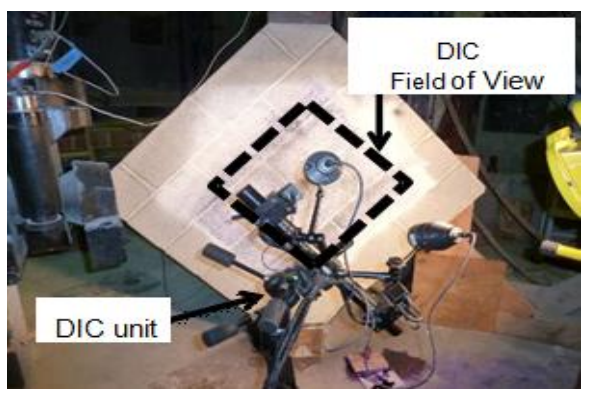

(f) DIC field of view (front)

Fig. 1 Assemblages test setup

TML gages were placed along the vertical and horizontal directions of the specimens. The load was applied uniformly in constant intervals using a vertical MTS actuator operated in force control. It should be noted that the DIC field of view (sketched in Fig. 1f) was restricted to a region of $609 \times 609 \mathrm{~mm}$ due to the length of the mounting bar of the DIC system. Consequently, no direct comparison was possible between the estimated DIC strain (gage length $\sim 609 \mathrm{~mm}$ ) and the elongation measured by the TML gages covering the entire length of the specimen diagonal (The gage length is $1.2 \mathrm{~m}$ ).

\subsection{DIC setup for assemblages}

The DIC setup consisted of a GOM Aramis 3D 5 megapixel camera system, containing two Baumer TGX15 cameras with peak acquisition frequency of $30 \mathrm{~Hz}$ for 3D measurements. Testing parameters including the field of view (FOV), object distance and camera angle were approximately $500 \times 400 \mathrm{~mm}, 780 \mathrm{~mm}$, and $23^{\circ}$, respectively. These parameters were optimized 
using tables provided by the manufacturer and a dedicated calibration block. The distance between two lenses was $308 \mathrm{~mm}$. A random speckle pattern was created on the surface by means of a rubber stamp pad. In order to determine the system's sensitivity, few pre-test images of the sample were taken. The sampling rate was 1 2 frames per second depending on the overall duration of each test. The noise level for strain measurement was approximately 30 micrometer/meter. A facet size of $25 \times 25$ pixels with a step size of 13 pixels was utilized to compute the results. Full-field strain patterns were recorded using the DIC system for assemblages. Although up to 500 snapshots were collected during each test, for the sake of brevity, only the images that show the measured full-field strain contours near failure are presented here.

\subsection{Wall configuration and test setup}

The details of the full-scale partially grouted masonry shear wall are tabulated in Table 1. One horizontal actuator at the top and two vertical actuators on either sides of the wall transferred the load and displacement through two stiff steel beams that were post-tensioned to the wall as shown in Fig. 2. The wall was tested under 0.14 MPa axial compression stress and linear cyclic lateral displacement as illustrated in Fig. 2c. Both the vertical and horizontal grouted cells of the wall contained one D19 bar (19 mm diameter) placed at every $1.8 \mathrm{~m}$. The horizontal and vertical reinforcement ratio of the wall was $0.08 \%$ and $0.11 \%$, respectively (see $[6,7,8]$ for more detail). In order to prevent out of plane motions, the top of the wall was restrained with hinged out-ofplane supports. Two additional courses were built above the target height of the wall to provide enough development length for the vertical bars (using 90 degree hook in the last course). According to MSJC 2013 [33] the wall can be categorized as ordinary reinforced masonry (ORM). Fig. 2b depicts instrumentation setup used to record the wall deformations. Linear Variable Differential Transformer (LVDT, Schaevitz DC-SE 4000) and strain-gage based displacement transducers (TML, CDP-25) were used to measure and record the wall displacements and deformations using OPTIM data acquisition system.

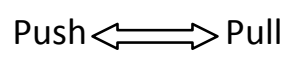



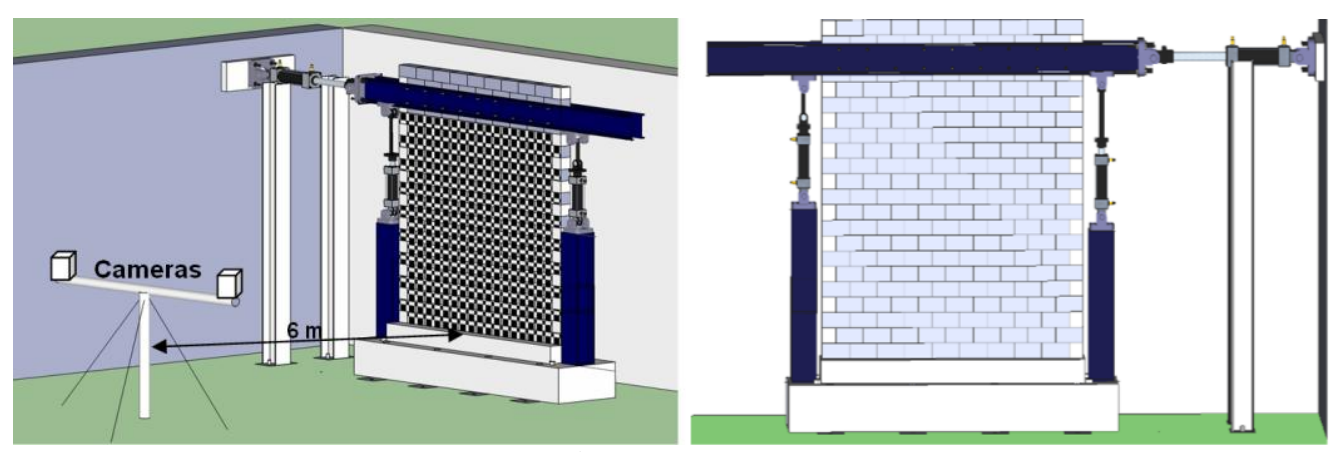

(a) Wall and DIC test setup, front and back

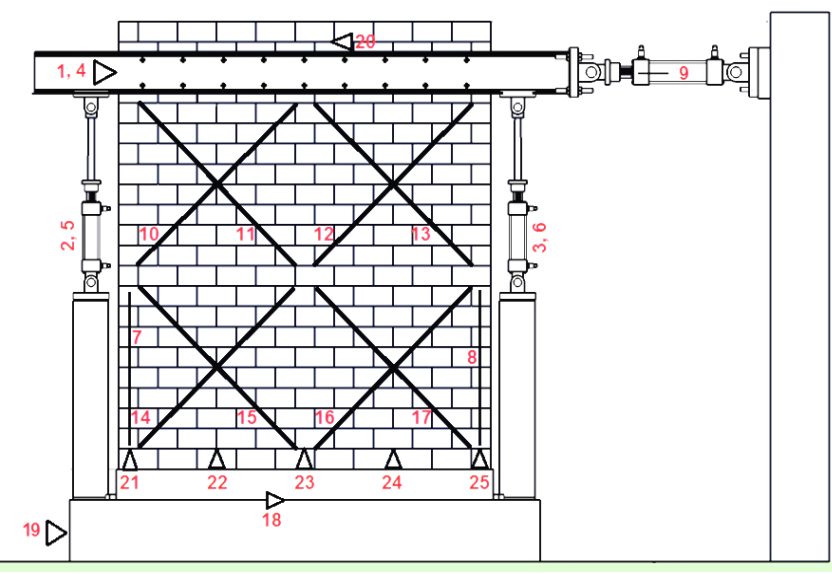

(b) Instrumentation at the back of the wall

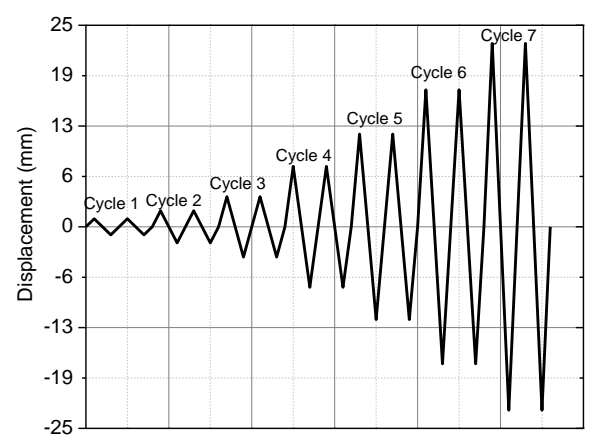

(c) Displacement history

Fig. 2 Test setup, instrumentation and loading protocol

DIC images were recorded using an ARAMIS 3D 5-megapixel camera system. The cameras were mounted on a custom-made supporting bar positioned $6 \mathrm{~m}$ away from the tested walls. Two camera lenses were separated by a distance of $1.9 \mathrm{~m}$. The cameras were calibrated for a field of view of $4 \times 4 \mathrm{~m}$ using a dedicated calibration cross. The noise level for strain measurements was consistently measured to be approximately 100 microstrain. Due to the ambient lighting conditions, an exposure of 200 milliseconds was utilized according to the available. A random speckle pattern was applied on the front surface of the wall using spray paint and commercially available perforated sheets. A facet size of 35 pixels and step of 17 pixels were used $\mathrm{f}$ to measure the strains. .The images were recorded with a sampling rate of 1 frame/second. 
The test was conducted under quasi-static displacement controlled loading. Reversed displacement cycles were applied at the top of the wall (Fig. 2c). In order to monitor strength and stiffness degradation of the wall, two cycles were applied at each drift .

Table 1 Dimensions and reinforcement configuration of the wall

\begin{tabular}{ccccccc}
\hline $\begin{array}{c}\text { Height } \\
(\mathrm{m})\end{array}$ & $\begin{array}{c}\text { Length } \\
(\mathrm{m})\end{array}$ & $\begin{array}{c}\text { Width } \\
(\mathrm{m})\end{array}$ & $\mathrm{h} / \mathrm{l}$ & \multicolumn{2}{c}{ Reinforcement } & Reinforcement \\
\cline { 5 - 7 } & & Vertical & Horizontal & spacing $(\mathrm{m})$ \\
\hline 3.8 & 3.8 & 0.2 & 1 & 1D19 & 1D19 & 1.8 \\
\hline
\end{tabular}

\section{Experimental results and discussions}

\subsection{Assemblages}

Prisms- The failure mode of the ungrouted prisms was characterized by the vertical tensile splitting cracks initiating at the middle web, spreading to the top and bottom of CMUs. For the fully grouted specimen, the failure mode was characterized by diagonal crack. Splitting failure and vertical cracking in the axially compressed ungrouted and fully grouted prism are shown in Fig. 3 and Fig. 4. The color map illustrates the horizontal " $x$ " strain component. The DIC measured strain was evaluated by considering two points at the middle of the top and bottom of CMUs which is the virtual gage that "mirrors" the TML gage from the other side. Fig. 3a shows the comparison between the stress-strain curves. The strain was extracted using the moving averages of both the DIC and TML gages for the ungrouted specimen. The full-field strain visualization of the fully grouted specimen before the final fracture is also presented in Fig. 3d. Large deformations were observed at the incipient failure state along the vertical crack, which is visible in the overlapped picture of both specimens. DIC strain readings were consistently lower than the TML strain measurements. These discrepancies could be attributed to a slight eccentricity in the vertical axial load which was not fully resolved by capping the specimen. . Unavoidable eccentricity resulted in an uneven strain distribution in the front and back surfaces. A similar trend was observed in the axial compression test of the fully grouted prism. The strain visualizations corresponding to the three stages, (1) elastic, (2) before damage and, (3) failure are shown in Fig. 3a-d. 


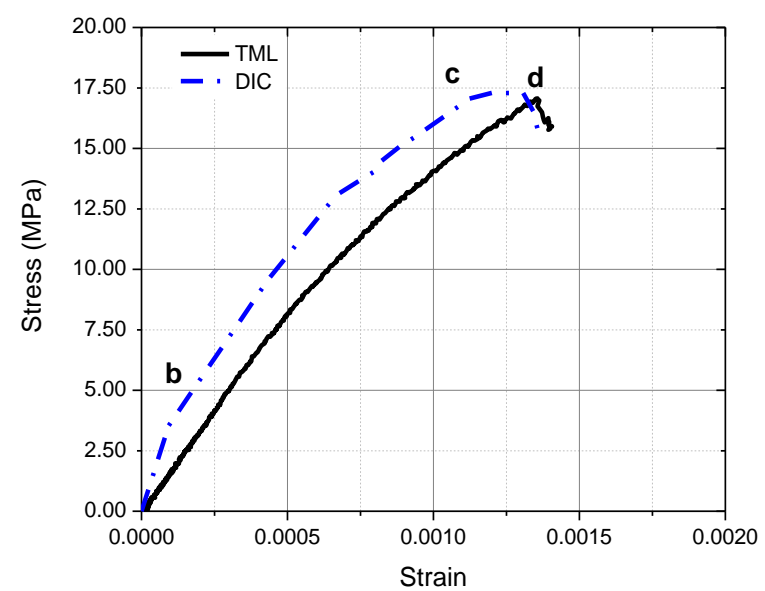

(a) Stress-strain curve comparison

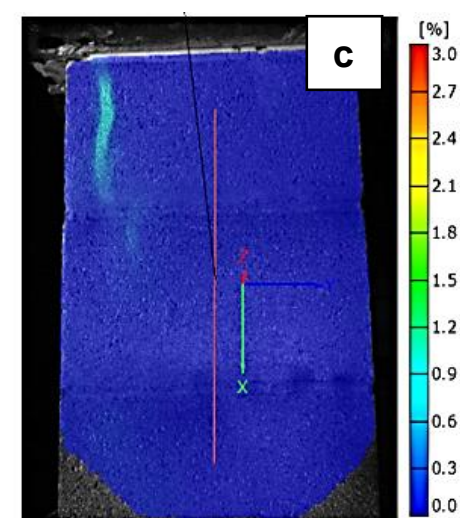

(c) DIC strain contour at incipient failure stage

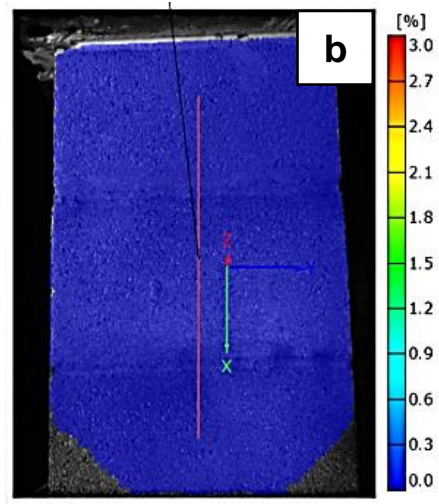

(b) DIC strain contour at elastic stage

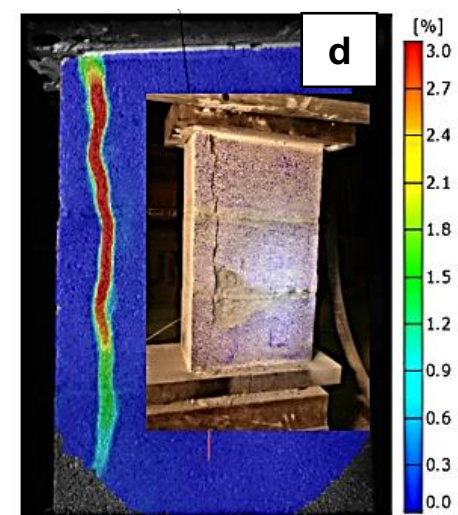

(d) DIC strain contour at failure stage

Fig. 4 Fully grouted prism stress-strain curve and strain contour

Even though minor differences were observed betweenthe DIC stress-strain and the TMLs, a satisfactory match was obtained between the final crack patterns and stress-strain curves of the broken specimens and TML outputs. 
Bed-joint shear- Large strains were observed along the bedjoint for both the ungrouted and fully grouted specimens, which led to failure by shear slip along the same critical planes. While the fully grouted specimen was failed in a very similar manner, some cracks developed throughout the CMUs. The ultimate shear stress of the ungrouted triplet specimen was lower than the fully grouted specimen. Maximum strain measured at failure for the ungrouted specimen was less than 150 microstrains (see Fig. 5a) Ungrouted specimens were brittle and failed at very low strain levels since they could only resist the shear through mortar.As a result, the difference between DIC and TML was high at the beginning of the test and was decreased as the test continued. The maximum strain of fully grouted specimen was 450 microstrain (Fig. 5b) and the DIC readings were consistent with the TML during the test. At incipient failure state, higher strain values were observed at the bed-joints along the interface between mortar and CMUs for both specimens. The DIC results were in a good agreement with the TML measurements.
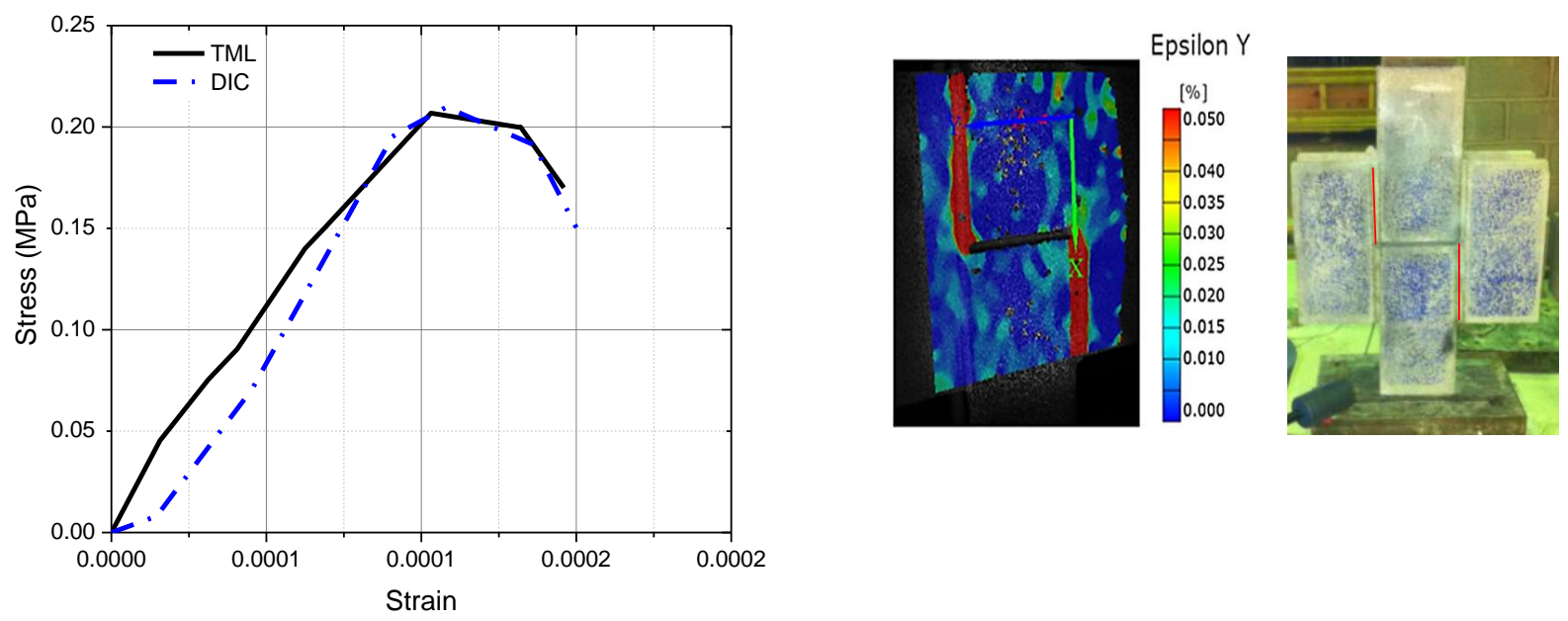
(a) Ungrouted
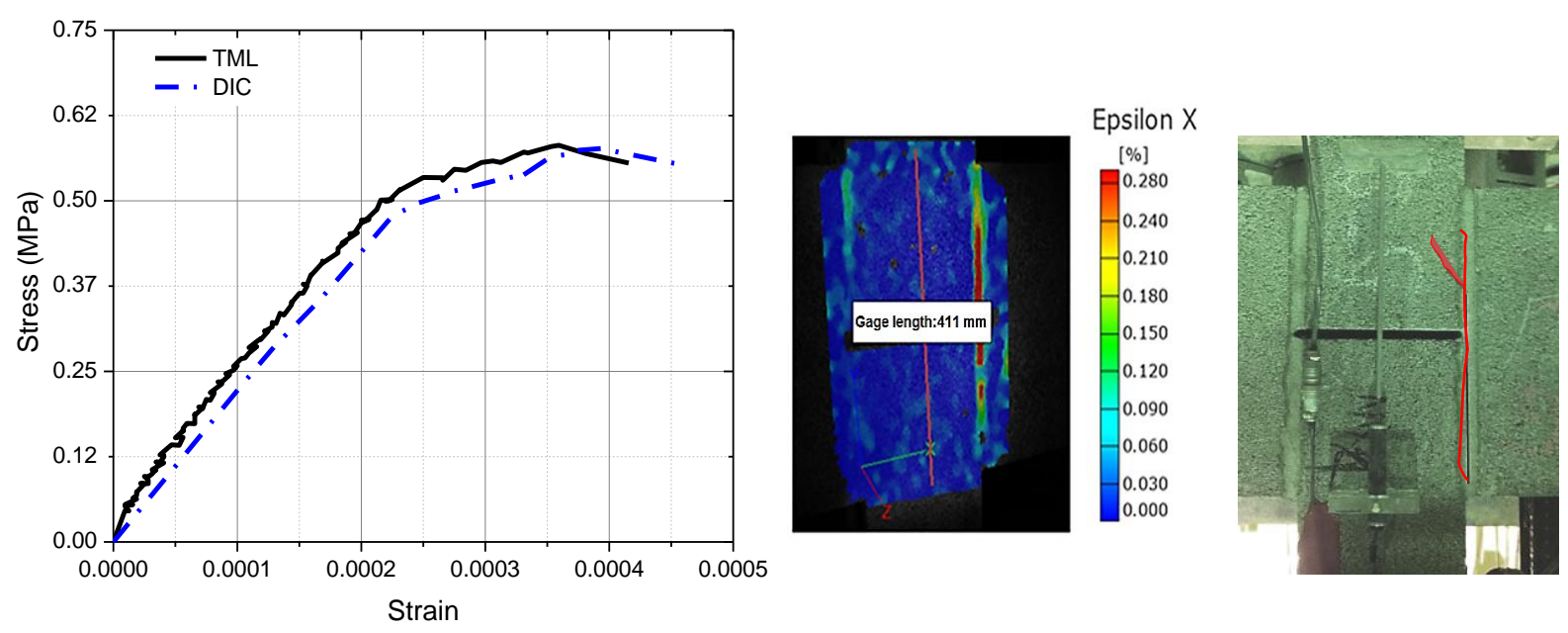

(b) Fully grouted

Fig. 5 Stress-strain curves of DIC and TML gage, DIC strain contours and specimen at incipient failure

Diagonal compression- The strain contour at incipient failure and the failure mode for the ungrouted specimensare depicted in Fig. 6. The results indicated the capability of the DIC in identifying the regions with strain concentration and accumulation along the bed-joints, thereby identifying locations where failure eventually takes place. The failureoccurred along these weak bed and head joints. The maximum strain value measured during the test by the TML gage (with a gage length of $1.2 \mathrm{~m}$ ) was larger then the strain estimated by the DIC. This can be attributed to the longer gage length. A 406x406 mm DIC field of view was considered in the test which restricted the gage length to about $508 \mathrm{~mm}$. Consequently, an exact comparison between the TML gage and the DIC was not possible. The load versus displacement curves were obtained for the diagonal compression test of the ungrouted specimen. The results showed that the specimen displacement, at a maximum load of $140 \mathrm{kN}$, was $0.24 \mathrm{~mm}$, compared to $0.3 \mathrm{~mm}$ obtained from TML. A sum comparison for the fully grouted specimen was not possible. 


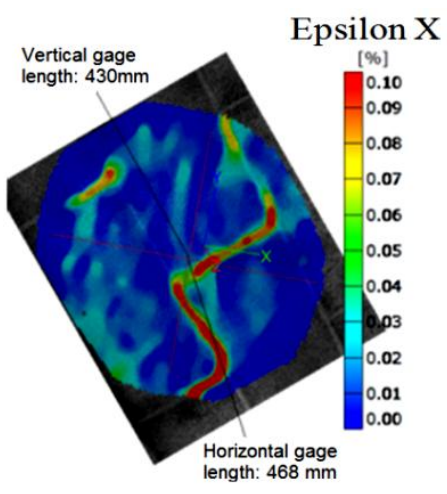

(b) DIC strain contour

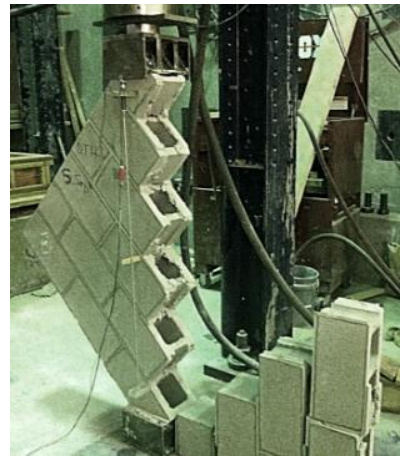

(c) Failure mode

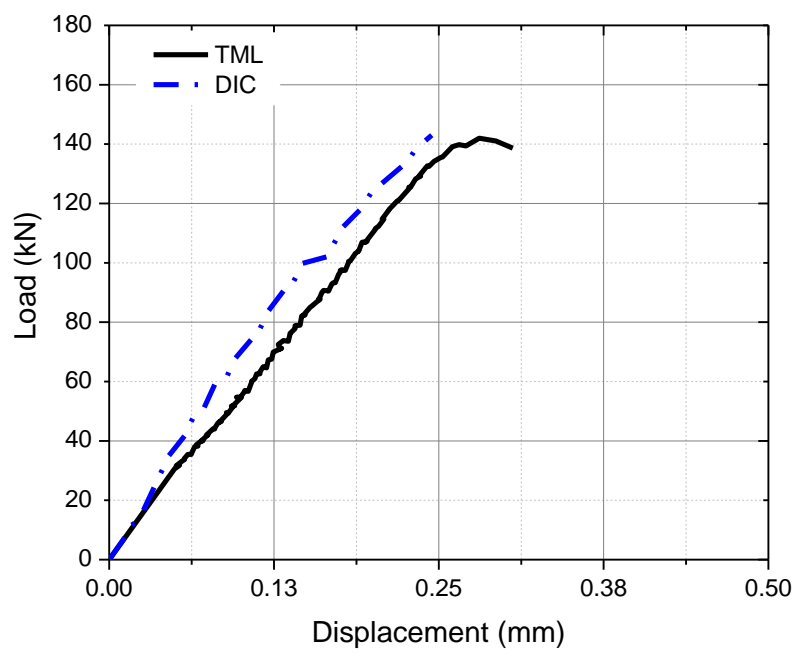

(a) Load-displacement curve comparison between DIC and TML gage

Fig. 6 Diagonal compression test for ungrouted specimen

\subsection{The wall}

Wall deformability- Deformability of reinforced masonry walls has been studied by many researchers including $[38,41]$. However, studies have on the deformation mechanism of the wall are inadequate. This is mainly because of the limitation on the number of sensors that can be implemented. Posture assessment of deformed walls during the test can significantly enhance our understanding of the wall failure mechanism. Therefore, in this study, the shape of the deformed wall is studied in addition to measuring the wall deformability.. According to the loaddisplacement curve, presented in Fig. 7, the deformability of the wall was $23 \mathrm{~mm}$ at the end of the test. 


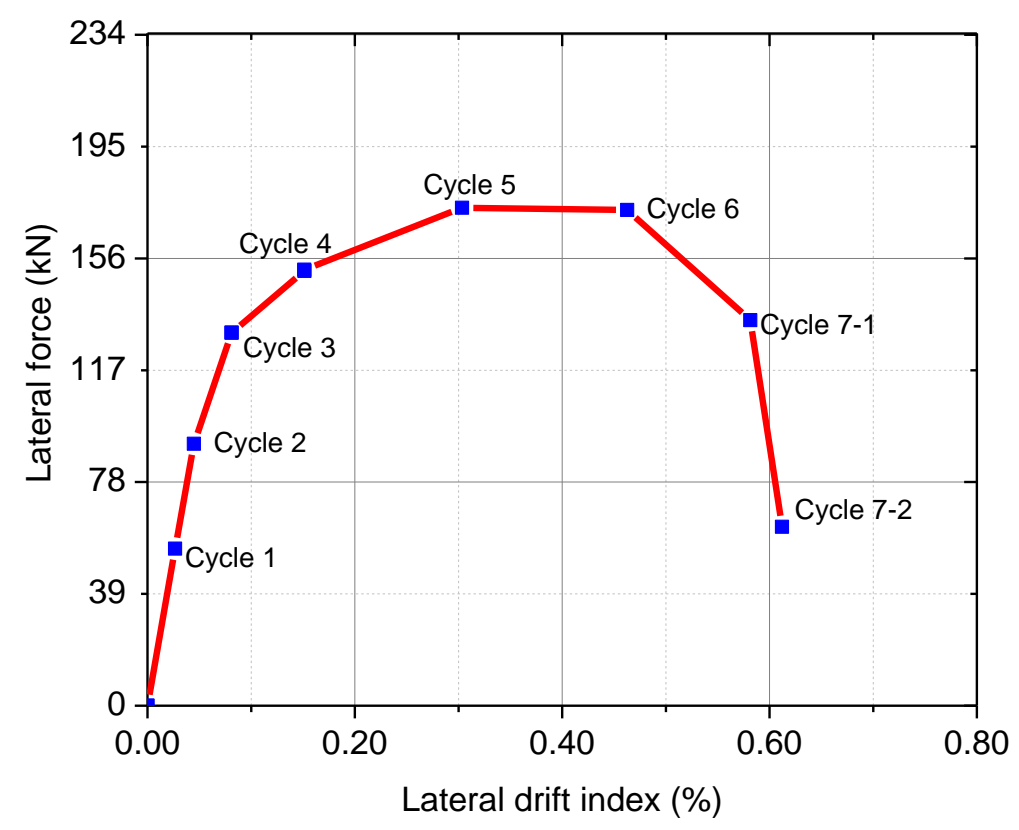

Fig. 7 load-drift envelope curve of the wall

To investigate the wall deformation behavior in more depth,, two imaginary points were designated at the top and middle of the wall during the data processing. Displacements of the points, in the $\mathrm{X}$ and $\mathrm{Y}$ directions, were tracked during the test and the results are shown in Fig. 8. In the elastic region, displacement of point $\mathrm{B}$ in the $\mathrm{X}$ direction was greater than the point $\mathrm{A}$ which is associated with the cycle three. In contrast, in the $\mathrm{Y}$ direction, displacements of these points were exactly the same in the elastic region. The difference increased as the lateral displacement increased. Additionally, the displacements in Y direction increased in the first five cycles and decreased during the last two cycles (Fig. 8b). The combined $\mathrm{X}$ and $\mathrm{Y}$ displacements of point $\mathrm{A}$ and $\mathrm{B}$ are shown in Fig. 9.Points $\mathrm{A}$ and $\mathrm{B}$ only moved in the horizontal direction during tension. However, during the compression cycles, vertical displacements were larger and a linear relationship was observed between displacements in $\mathrm{X}$ and $\mathrm{Y}$ directions. Magnified view of the tension part is illuastrated in Figs. 8c,d. Although the 0.14 MPa axial load was applied at the top of the wall, points A and B started swelling up during the first few cycles. This can be attributed to the interlocking effect of the ungrouted CMUs. The maximum swelling of the wall was measured to be $0.5 \mathrm{~mm}$. After the fifth cycle, this swelling was decreased to zero and reached a negative value $(-1 \mathrm{~mm})$ at the end of the test. The 
mortar bed-joint and the wall toe crushing caused a drop in displacement during the last cycles. Plotting the displacements of point $\mathrm{A}$ and $\mathrm{B}$ in the $\mathrm{X}$ and $\mathrm{Y}$ directions, showed that the fifth cycle plays an important role on the failure mechanism of the wall. The onset of the change in the failure behavior is indicated by the displacement swelling shift from a positive to a negative value. No sign of failure was observed up to this point. However, imposing a higher displacement resulted in diagonal cracks and mortar crushing. This behavior was coincided with an increase in the energy dissipation of the wall and enlarging the size of the cracks. This issue will be discussed further in the following section.

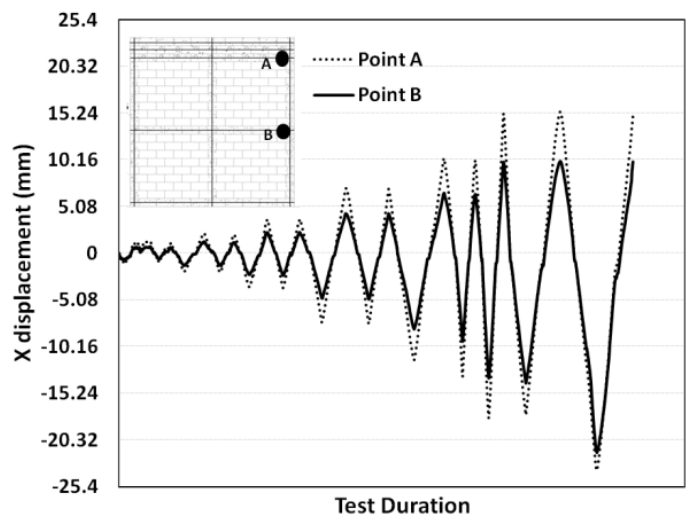

(a) X displacement

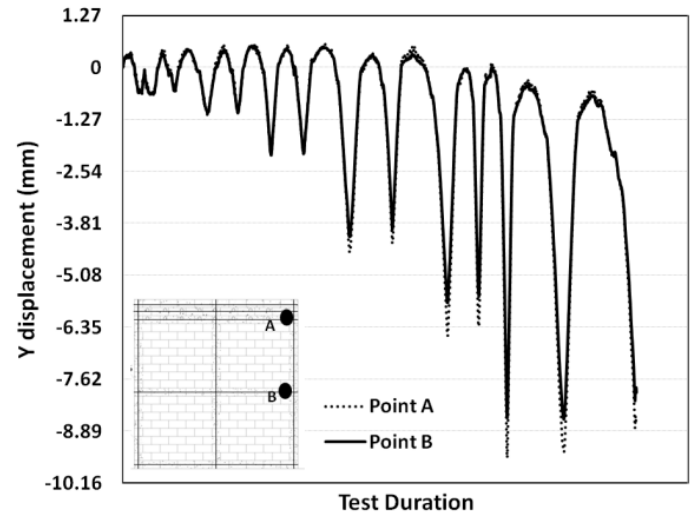

(b) Y displacement

Fig. $8 \mathrm{X}$ and $\mathrm{Y}$ displacement of points $\mathrm{A}$ and $\mathrm{B}$

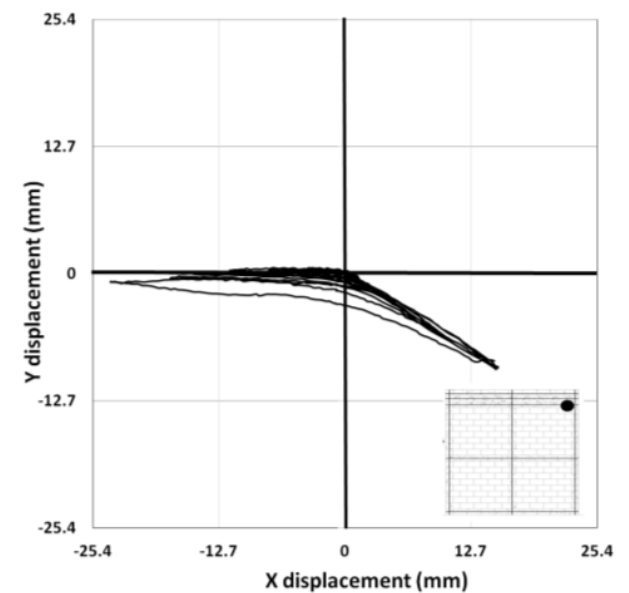

(a)

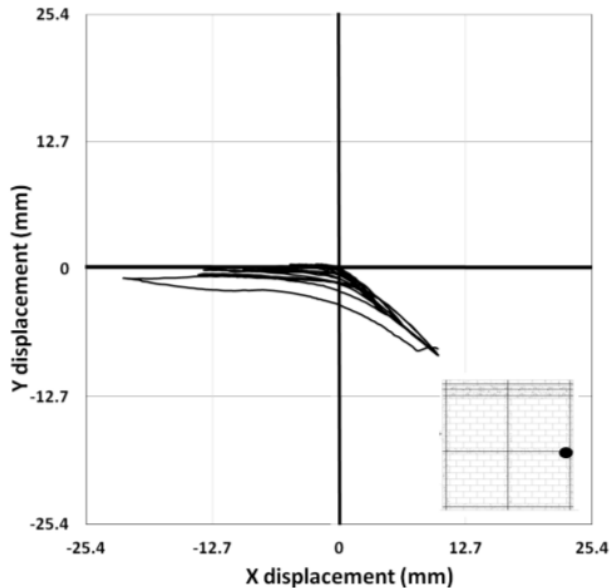

(b) 


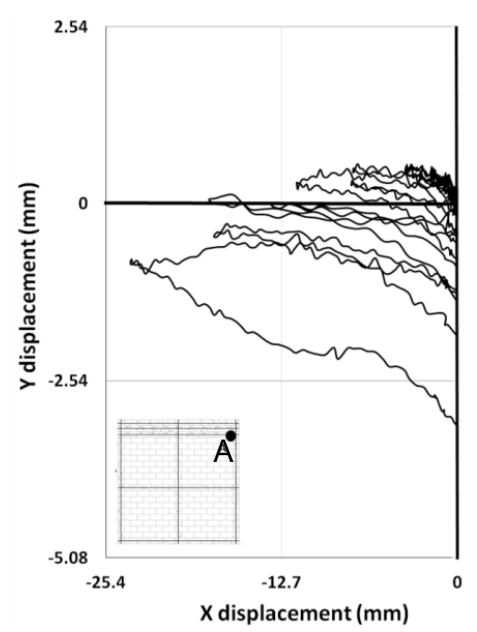

(c) Point A

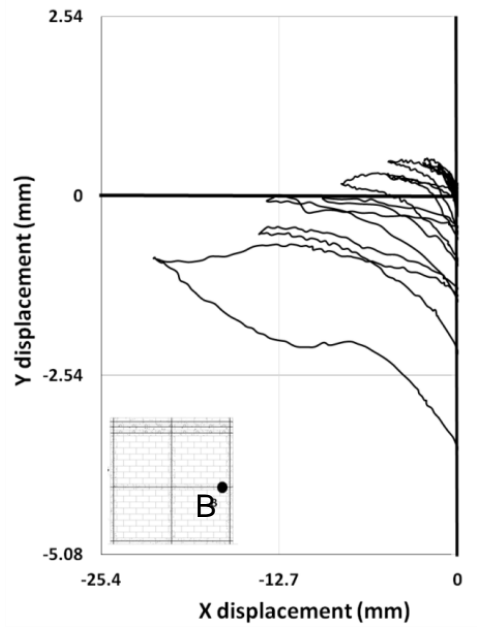

(d) Point B

Fig. 9 Displacement path of points A and B

Crack pattern- Fig. 10 shows the crack patterns of the wall at elastic, plastic, and damage phases. It should be noted that two cycles of each drift were applied. Therefore, all crack patterns referenced herein are related to the second cycles. Also, the maximum load of two cycles corresponding to each drift level was reported as the peak. The specimen behaved elastically up to $0.1 \%$ drift associated to a load of approximately $125 \mathrm{kN}$ (see Fig. 7). No cracks were observed at this drift level which is associated to the end of third cycle (Fig. 10a). The first signs of cracks were observed in mortar joints at $0.15 \%$ drift level, and as a result, the slope of the curve dropped and the wall began to show nonlinear behavior. At this level, the load capacity of the wall reached to $155 \mathrm{kN}$. The flexural horizontal cracks were formed at the bottom courses roughly around $0.15 \%$ drift (forth cycle). Diagonal zigzag de-bonding joint cracks developed in the ungrouted portion of the wall at the fifth cycle $(0.3 \%$ drift or $165 \mathrm{kN})$. This type of crack was similar to the one observed in the ungrouted diagonal compression specimen (Fig. 6). Diagonal cracks propagated in a step pattern due to mortar de-bonding at the bed and head joints. At the $0.45 \%$ drift, a few new cracks appeared at the wall toes and the widths of the previous cracks were increased. The wall experienced its maximum shear strength at the sixth cycle at a load of $175 \mathrm{kN}$. At the $0.45 \%$ lateral drift, vertical splitting cracks were observed. The size of step cracks increased and developed through the full diagonal length passing the bond beam and grouted cells, leading to strength and stiffness degradation. The shear-dominated behavior was observed. At the $0.6 \%$ drift level (cycle 7), new head and bed-joints cracks were initiated in the ungrouted panels and were extended into the grouted cells. 

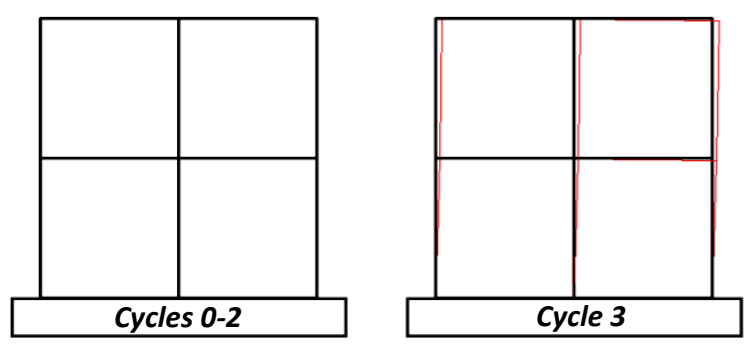

(a) Phase I, elastic
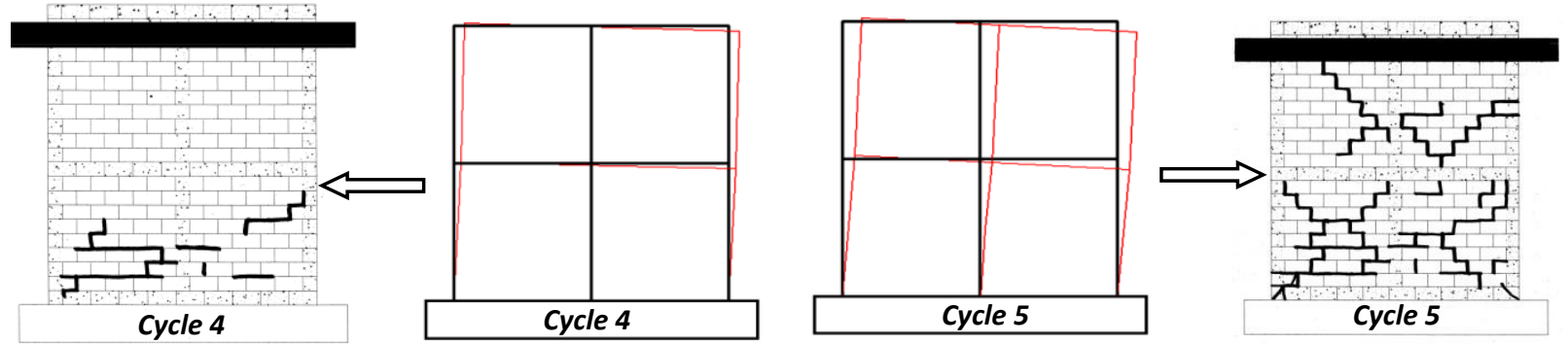

(b) Phase II, plastic
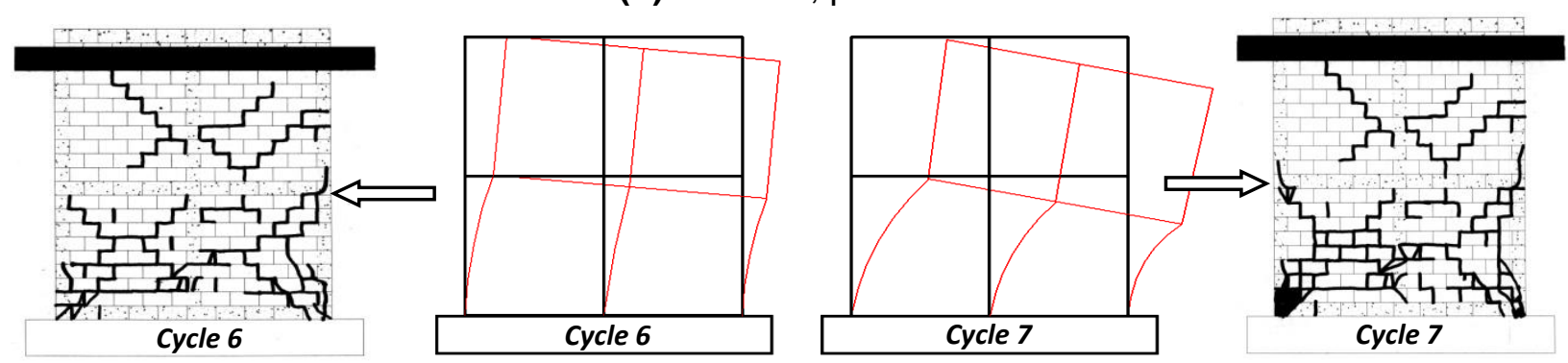

(c) Phase III, damage

Fig. 10 Wall deformation shape and related cracks

Splitting cracks and toe crushing were observed at this point and most of the cracks were occurred at the bottom of the ungrouted panels (Fig. 10c). Additionally, cracks with angle of 45 degree were observed at the toe of the wall at $0.6 \%$ drift level, which was corresponded to the last loading cycle. It should be noted that what was described for the cracks in this section is based on visual inspection. The results of DIC could provide quantitative measurements and additional understanding of the wall behavior. Since high resolution cameras were used, all the structural cracks on the wall surface were precisely captured. However, the strains lower than 
$0.2 \%$ cannot be easily observed, as shown in Fig. 11 (monochromic blue color is associated to strains $<0.2 \%$ ).However, the full-field strain contour given by DIC could helps distinguish all the structural cracks from the non-structural ones. The DIC results are referred to the front of the wall and are mirrored in respect to the crack pattern visually observed at the back of the wall. Consistent with the visual inspection, no signs of cracks were captured by DIC until the end of third cycle. By the end of the forth cycle, DIC imaging showed only one major structural crack at the bottom of the wall. This contradicts the crack pattern showed in Fig. 10b.

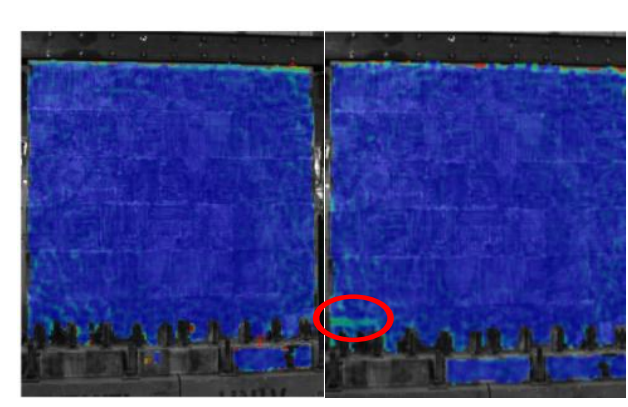

Cycle 0-3

Cycle 4

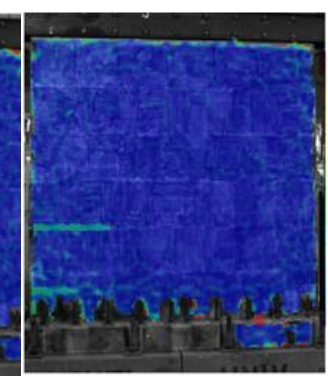

Cycle 5

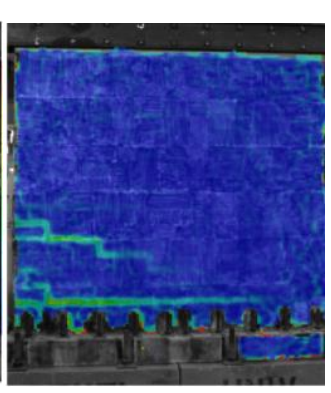

Cycle 6

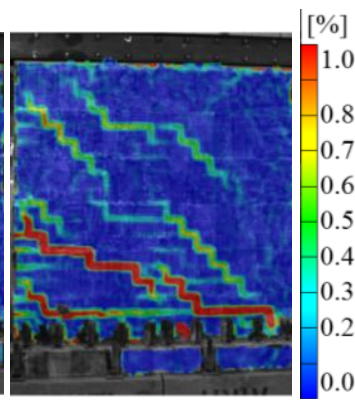

Cycle 7

Fig. 11 Crack propagation and strain contour

It should be noted that the DIC crack pattern referred to the peak load of each loading cycle, therefore cracks appear mainly on the left region of the wall. Similar to the forth cycle, in the fifth and sixth cycles, visual inspection highlighted a larger number of cracks with respect to DIC. However, the DIC crack pattern recorded at the peak load of the seventh cycle was almost similar to the visual crack pattern. The comparison between the final crack distribution and the DIC detected crack pattern is shown in Fig. 12a. Crack pattern differences between forth to sixth cycles can be justified by the presence of several non-structural (micro) cracks observed visually. These cracks show the potential path for the structural cracks in the presence of large displacement. To obtain further insight into the effect of the non-structural and structural cracks on the damage progress, the energy dissipation of the wall was correlated with the strain maps extracted by the DIC. For this purpose, lateral load-drift and energy dissipation-drift curves are plotted in Fig. 12b,c. 

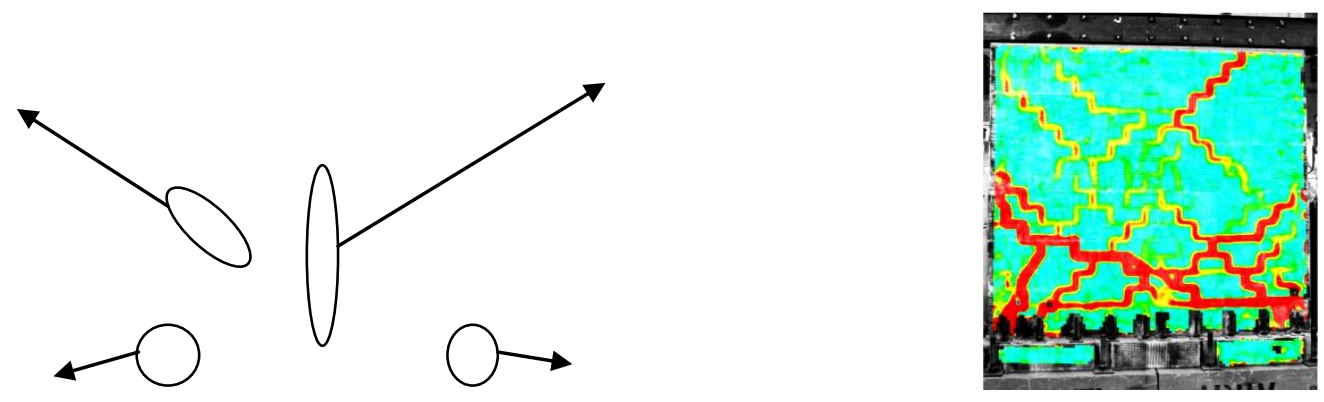

(a) Final crack pattern

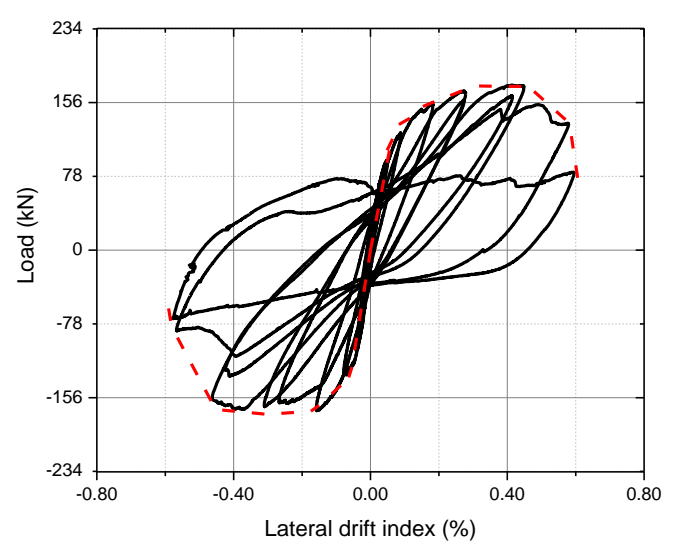

(b) Lateral load-drift

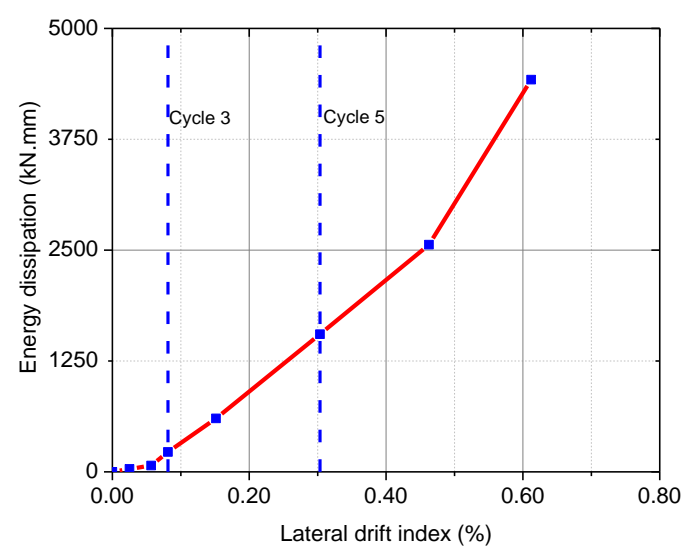

(c) Energy dissipation curve

Fig. 12 Crack pattern, hysteresis and energy dissipation of the wall

It can be seen that a small amount of energy, $200 \mathrm{kN}$.mm (Joule), was dissipated by the end of the third cycle. However, energy dissipation increased to $850 \mathrm{~J}$ at the end of the forth cycle which was almost four times larger than the third cycle. This trend continued throughout the test. Although energy dissipation value at the forth cycle was relatively high compared to the third cycle, there was no sign of diagonal cracks. The energy was dissipated only by propagation of the flexural cracks in the horizontal joints. However, in the fifth cycle, dissipated energy increased to a value more than $1 \mathrm{~kJ}$. After this point, the diagonal cracks were formed on the hollow panels. Additionally, the graph is showing that energy dissipation of the micro cracks was very small compared to that of the structural cracks. It can be concluded that some of the visual cracks can be misleading and DIC seems to capture the relevant structural cracks in the wall. 
Base strain- Measuring the strain distribution at the base of PG reinforced masonry walls could result in an accurate analytical model for calculating the flexural strength of the walls. This measurement is highly affected by the number of strain gages. Therefore, comparing the traditional point-to-point set of measurements with the full-field strain distribution can be useful. All the measured strains were plotted for the wall for both compression and tension cases. The results showed that the strain distribution at the base was linear up to the third cycle (phase I). Therefore, in the elastic analysis, the concept of linear strain distribution at the base of the walls can be used in order to calculate the flexural capacity. Fig. 13a shows the strain distribution at the bottom of the wall for all drift index levels using point-to-point measurements. This graph indicates that the axial strain distribution along the base of the wall is nonlinear in the phase II and III (plastic and damage). Nonlinearity is readily observable around the toe of the wall specifically in the case of compression. This is mainly due to severe damage that occurred at the left side of the wall. Therefore, once this region undergoes tension, the TML cannot record the deformation properly. It should be noted that because of discrete cracks, all the strain values shown in Fig. 13a may be somewhat affected by the 4 inches sensor gage length. To better visualize the strain distribution at the base of the wall, DIC results collected at TML locations were also plotted for both ends of the wall in the Fig. 12b. Symmetric strains were observed at both ends up to the third cycle. Point A (right side) showed a constant compressive strain (-0.5\%) after the third cycle during compression of the wall and this led to a higher tensile strain at the opposite side of the wall (point B). However, this is not the case for the point B (left side). Minaei et al. [42] measured the strain distribution at the drift level of $0.45 \%$ for a PG reinforced masonry shear wall. They reported that the strain distribution along the base of PG walls is nonlinear. Results of the DIC and TMLs at $0.45 \%$ and higher drift levels (or the sixth cycle) in the present study also confirm the nonlinear strain distribution at the base of the wall. 

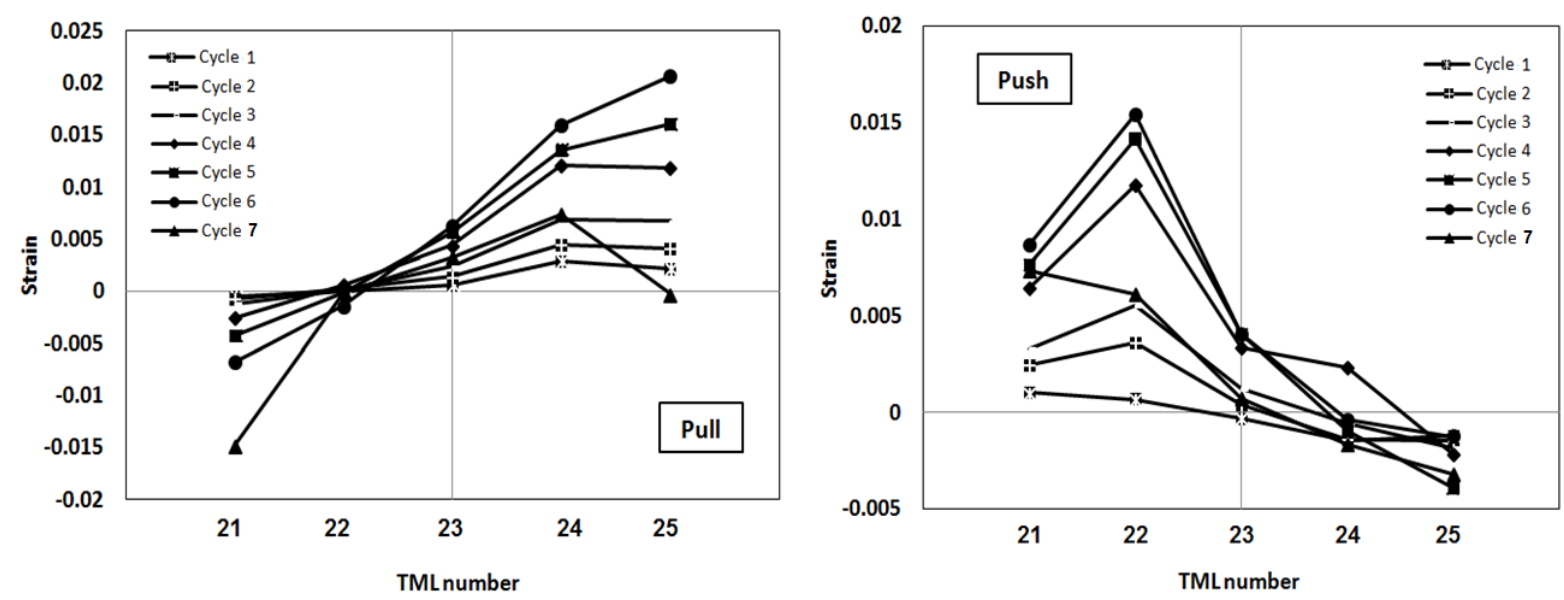

(a) Strains at the base of the wall using TMLs

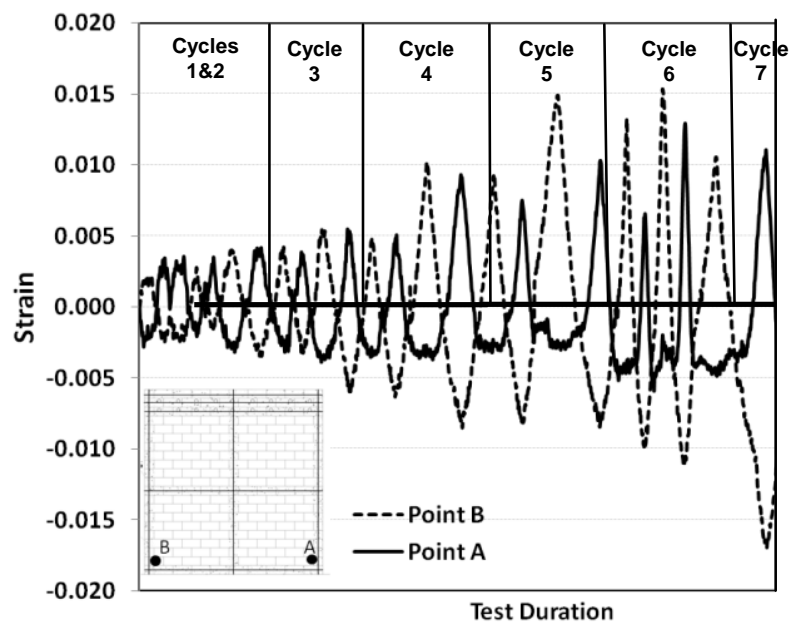

(b) Strains at the base of the wall using DIC

Fig. 13 Strain at the base of the wall

Panel deformation- Two cross strain gages (TMLs) were mounted at each ungrouted panel and the diagonal deformation of each panel was measured during the test. Similar measurements were attempted using DIC. As it can be seen in Figs. 14 a, b the DIC results are consistent with the TMLs, especially at the bottom panels until the last cycles. Due to the severe damage at the bottom panels, spalling and toe crushing, DIC results were more accurate than the TMLs. At the beginning of the test, compression diagonal displacement was small at the bottom panels. However, at the last cycle, the compressive displacement was increased to reach to the amount of tensile displacement. 
Diagonal tensile and compressive strains at the four ungrouted panels of the wall were measured by applying different displacement at the top of the wall during the test. As shown in Fig. 15, the tensional and compressional strains strains at the bottom panels were considerably larger than that of top panels. Additionally, comparing the results of ungrouted panels with the DIC crack patterns (see Fig. 11) indicates that small deformation recorded at the top ungrouted panels did not cause any major damage in the wall (strains are relatively less than $0.3 \%$ ). However, as lateral drift increased, the effect of structural cracks becomes more significant on the wall failure. This can be verified by comparing the panel diagonal strain with the DIC output. As shown in Fig. 15b, the diagonal tensile strains were less than $0.3 \%$ for all diagonal TMLs up to the fifth cycle $(0.3$ drift $)$. This indicates that there are no structural diagonal cracks throughout the wall. TMLs 14, 16, and 17 recorded diagonal strains larger than $0.3 \%$ at the sixth cycle $(0.45 \%$ drift). This indicates the presence of diagonal structural cracks in the mortar joints. The DIC results (Fig. 11) also revealed that the first diagonal crack was appeared in sixth cycle at the location of the TML 15. Therefore, all the other visible cracks recorded during the test have no significant effect on the failure mechanism of the wall. The effects of the structural cracks on the failure of the wall were achieved in a more accurate and efficient way by interpreting the DIC results. Although concrete crushings were observed at the toes of the wall in the last cycle, plotting the diagonal compressive strains of TMLs along with DIC results showed that there are no sign of crushing in the diagonal TMLs path (all strain values were less than $0.3 \%$ except for TML 15).
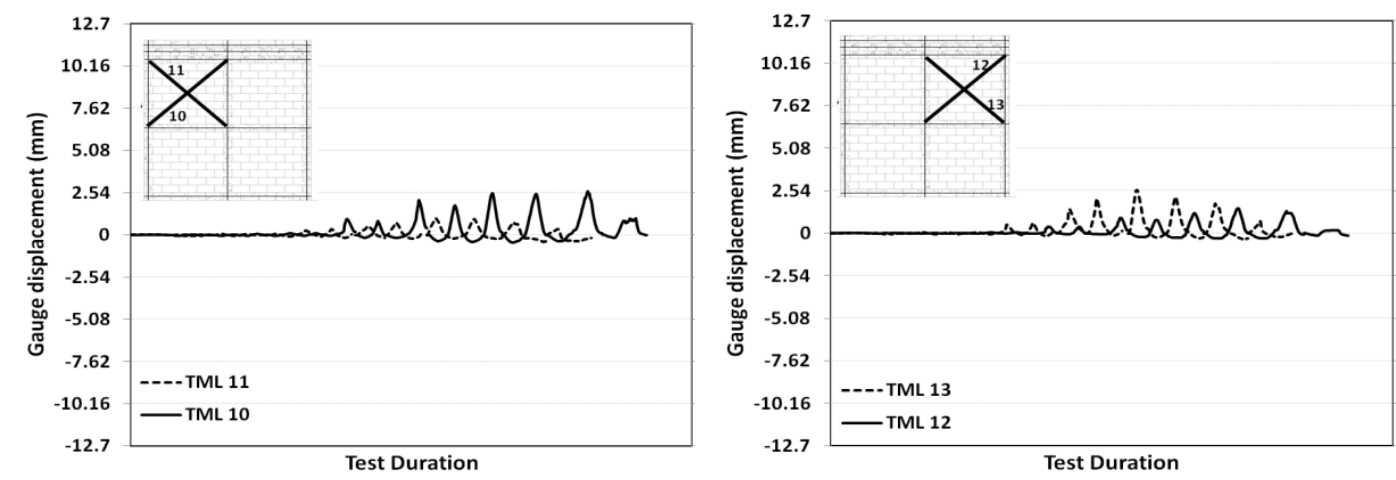

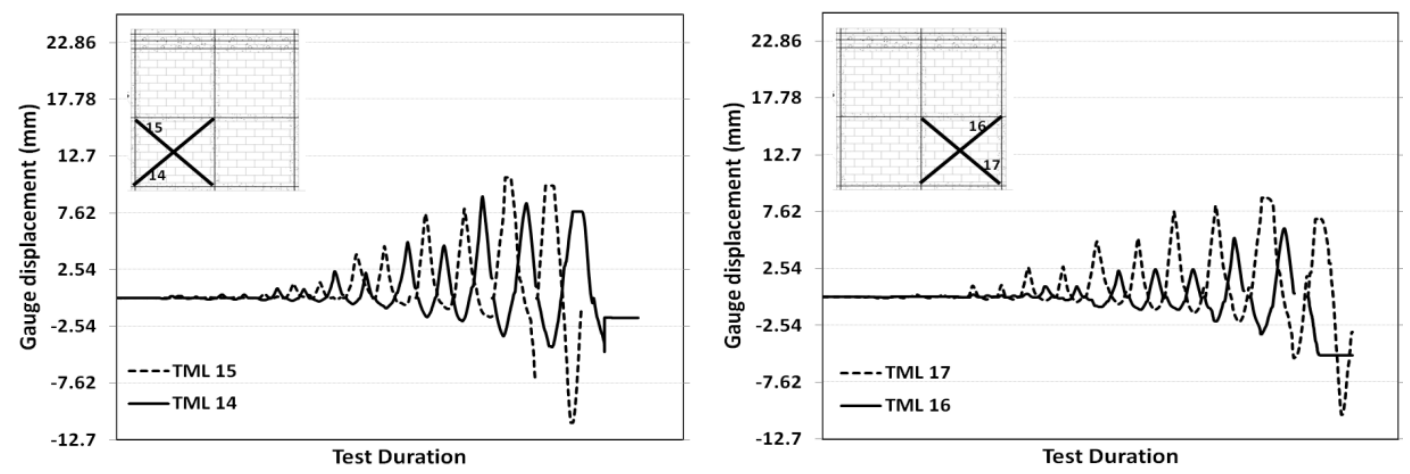

(a) Panel deformation using TML
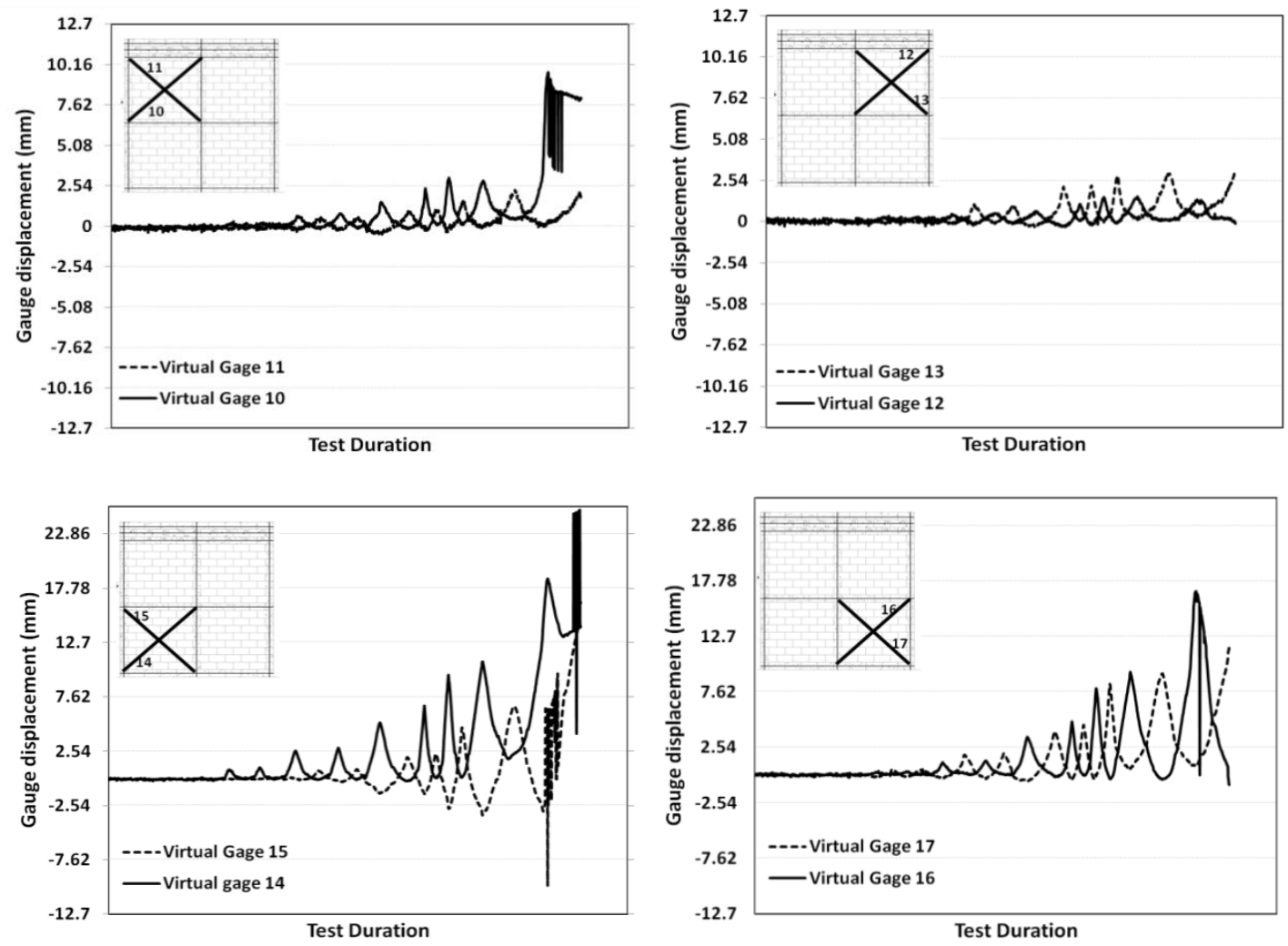

(b) Panel deformation using DIC

Fig. 14 Panel deformation
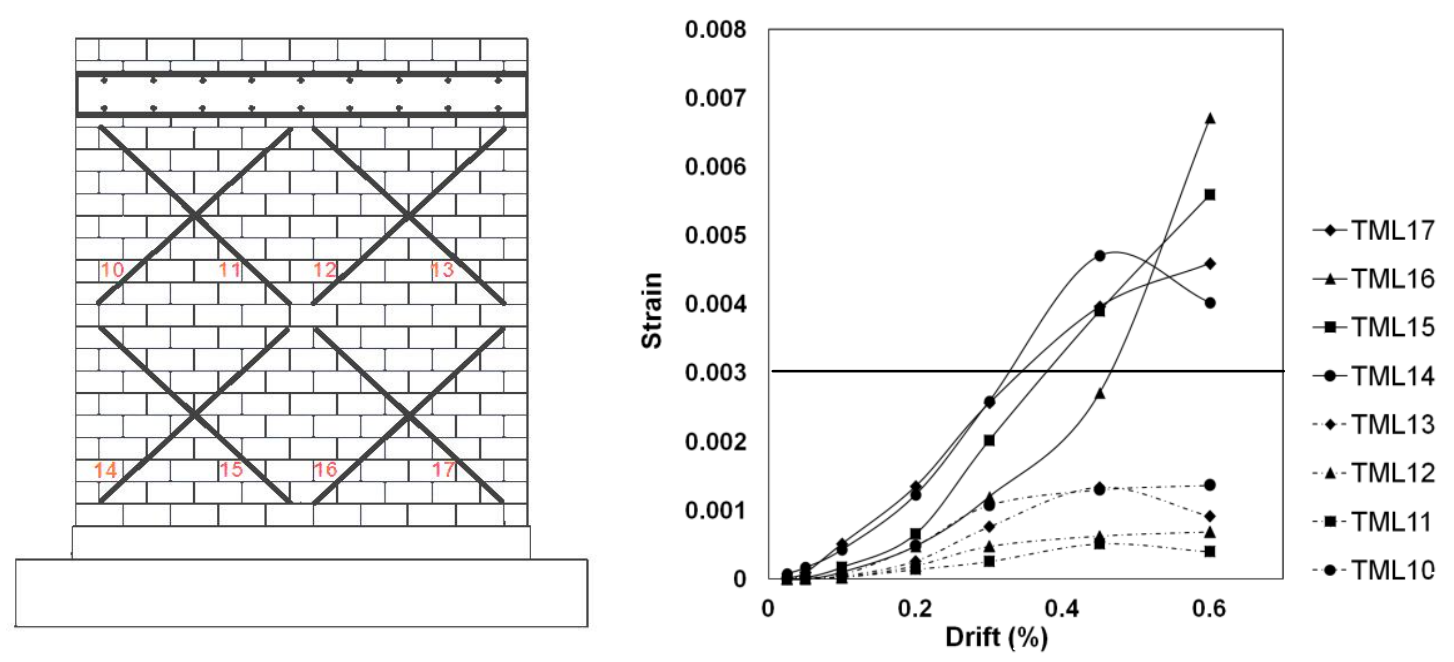
(a) TML positions

(b) Diagonal tension vs. drift

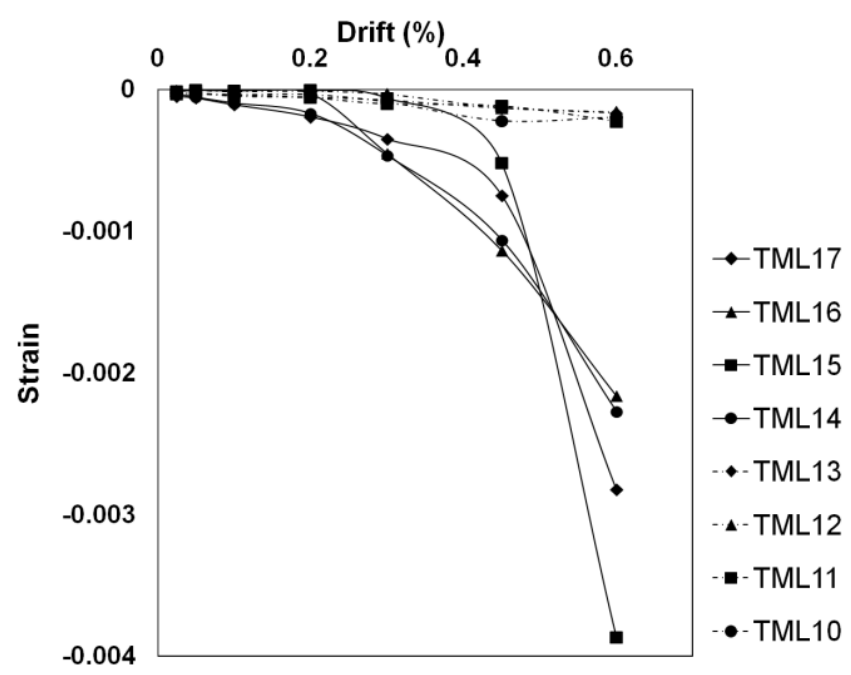

Fig. $15 \mathrm{TML}$ positions and diagonal strains in the panels

\section{Conclusions}

A set of ungrouted and grouted concrete masonry assemblages, along with a partially grouted masonry wall, was constructed and tested. By leveraging traditional sensing and digital image correlation (DIC), the following conclusions were drawn:

The DIC method was successfully implemented to quantify the non-uniform strain contours of the concrete masonry assemblages estimating their surface deformation. In addition to monitoring the strain across the gage length of traditional wired gages, the DIC method mapped the full-field deformation and the damage by highlighting the maximum strain spots at the locations of incipient and progressive failure. Visually mapped final crack patterns were consistent with the DIC patterns and the DIC strain of ungrouted panels showed good correlation with the strain values measured by the TML. It was concluded that the full-field measurements using DIC is promising especially when the test specimens experience high inelastic deformation. Quantitative mapping of deformation field to the wall capacity was only possible 
by using DIC. In addition to monitoring strains across the gage length, the DIC method provided a full-field quantitative strain map of the test specimens to the wall capacity and revealed strain hot-spots associated with the maximum strain at locations that corresponded to cracks. Characterizing the deformation mechanism and crack propagation of the PG reinforced masonry wall was performed by depicting strain distribution and the cognition of cracks associated with the wall capacity and strains more than $0.3 \%$ (called structural cracks herein), respectively. Additionally, results of energy dissipation and diagonal strain distributions indicated that the effect of micro cracks (appearing in the elastic and plastic zones) are negligible compared to the structural cracks. Therefore, some of the visually obtained crack patterns can be misleading even when they are large and the structural cracks captured by the DIC seemed to be more relevant. Results showed that the strain distribution at the base of the wall is linear in the elastic zone. Therefore, in the elastic analysis, the concept of linear strain distribution at the base of PG walls can be used in order to calculate the flexural strength of such walls.

\section{Acknowledgments}

This project is supported by a grant from National Science Foundation (NSF) Grant No. 1208208. The support of Delaware Valley Masonry Institute and Sabia Mason Contractors in providing the mason to build the test specimens is acknowledged. Part of the DIC equipment used during the experimental work was funded from the American Society for Non Destructive Testing. Opinions expressed in this paper are those of the authors and do not necessarily reflect the opinions of the sponsors.

\section{References}

[1] Nolph S, ElGawady M. Static cyclic response of partially grouted masonry shear walls. Journal of Structural Engineering, 2012;138(7):864-879.

[2] Schultz AE. Seismic resistance of partially grouted masonry shear walls. In: The Worldwide Advances in Structural Concrete and Masonry; 1996.

[3] Bolhassani M, Hamid AA, Johnson C, Schultz AE. Shear strength expression for partially grouted masonry walls. Engineering Structures Journal, doi:10.1016/j.engstruct.2016.09.001.

[4] Bolhassani M, Hamid AA, Johnson C, Moon FL, Schultz AE. New design detail to enhance the seismic performance of ordinary reinforced partially grouted masonry structures. $\mathrm{J}$. Struct. Eng., 10.1061/(ASCE)ST.1943-541X.0001620, 04016142.

[5] Rajaram S, Vanniamparambil PA, Khan F, Bolhassani M, Koutras A, Bartoli I, Moon F, Hamid A, Benson Shing P, Tyson J, Kontsos A. Full-field deformation measurements 
during seismic loading of masonry buildings. Structural Control and Health Monitoring. 2016.

[6] Bolhassani M, Hamid AA, Moon FL. Enhancement of In-Plane Capacity of Partially Grouted Concrete Masonry Shear Walls. Engineering Structures Journal, doi: 10.1016/j.engstruct. 2015.11.017.

[7] Bolhassani M, Hamid AA, Moon FL. Enhancement of seismic performance of partially grouted reinforced masonry shear walls. 10th US National Conference on Earthquake Engineering, Anchorage, Alaska; July 21-25, 2014.

[8] Vanniamparambil PA, Bolhassani M, Carmi R, Khan F, Bartoli I, Moon FL, Hamid AA, Kontsos A. A data fusion approach for progressive damage quantification in reinforced concrete masonry walls. Smart Materials and Structures, no. 1 2014: 23: 015007.

[9] Khan F, Rajaram S, Vanniamparambil PA, Bolhassani M, Hamid AA, Kontsos A, Bartoli I. Multi-sensing NDT for damage assessment of concrete masonry walls. Structural Control and Health Monitoring, no. 3, 2015; 22: 449-462.

[10] Khan F, Bolhassani M, Kontsos A, Hamid AA, Bartoli I. Modeling and experimental implementation of infrared thermography on concrete masonry structures. Infrared Physics \& Technology, 2015; 69: 228-237.

[11] Naeim F. The seismic design handbook. Springer Science \& Business Media, 1989.

[12] Nateghi-Alahi F, Khazaei-Poul M. Experimental study of steel plate shear walls with infill plates strengthened by GFRP laminates. Journal of Constructional Steel Research. 2012 Nov 30;78:159-72.

[13] Mogawer WS, Booshehrian A, Vahidi S, Austerman AJ. Evaluating the effect of rejuvenators on the degree of blending and performance of high RAP, RAS, and RAP/RAS mixtures. Road Materials and Pavement Design. 2013 Aug 1;14(sup2):193213.

[14] Vahidi S, Mogawer WS, Booshehrian A. Effects of GTR and treated GTR on Asphalt binder and high-RAP mixtures. Journal of Materials in Civil Engineering. 2013 May 23;26(4):721-7.

[15] Poul MK, Nateghi-Alahi F, Zhao XL. Experimental testing on CFRP strengthened thin steel plates under shear loading. Thin-Walled Structures. 2016 Dec 31;109:217-26.

[16] Binda L, Facchini M, Roberti G Mirabella, Tiraboschi C. Electronic speckle interferometry for the deformation measurement in masonry testing. Construction and Building Materials, 1998; 12(5):269-281.

[17] She AC, Hjelmstad KD, Huang TS. Structural damage detection using stereo camera measurements. Nondestructive Evaluation of Civil Structures and Materials, 1998; 345356.

[18] Carpinteri A, Lacidogna G. Damage monitoring of an historical masonry building by the acoustic emission technique. Materials and Structures, 2006; 39:161-167.

[19] Popovics J S. NDE techniques for concrete and masonry structures. Prog. Struct. Engng Mater, 2003; 5:49-59.

[20] Vanniamparambil PA, Bartoli I, Hazeli K, Cuadra J, Schwartz E, Saralaya R, Kontsos A. An integrated SHM approach for crack growth monitoring. Journal of intelligent material systems and structures, 2012; 23(14):1563-1573.

[21] Sutton MA, Walters WJ, Peters WH, Ranson WF, McNeil SR. Determination of displacements using an improved digital correlation method. Image and Vision Computing, 1983; 1(3):133-139. 
[22] Sutton MA, Orteu JJ, Schreier HW. Image correlation for shape, motion and deformation measurements: basic concepts, theory and applications, Springer, 2009.

[23] Pan B, Qian K, Xie H, Asundi A. Two-dimensional digital image correlation for in-plane displacement and strain measurement: a review. Measurement Science and Technology, 2009; 20(6):062001-062001.

[24] Cofaru C, Philips W, Paepegem W Van. Improved Newton-Raphson digital image correlation method for full-field displacement and strain calculation. Applied optics, 2010; 49(33):6472-84.

[25] Chu TC, Ranson WE, Sutton MA, Peters WH. Applications of digital-image-correlation techniques to experimental mechanics. Experimental mechanics, 1985; 25(3):232-244.

[26] Luo PF, Chao YJ, Sutton MA, Peters Lii WH. Accurate measurement of three-dimensional deformations in deformable and rigid bodies using computer vision. Experimental mechanics, 1993; 33:123-132.

[27] Sutton MA, Turner JL, Bruck HA, Chae TA. Full-field representation of discretely sampled surface deformation for displacement and strain analysis. Experimental mechanics, 1991; 31(2):168-177.

[28] Bruck HA, McNeill SR, Sutton MA, Peters Lii WH. Digital image correlation using Newton-Raphson method of partial differential correlation. Experimental mechanics, 1989; 28(3): 261-267.

[29] Peters Lii WH, Ranson WF. Digital imaging techniques in experimental stress analysis. OPT. ENG., 1982; 21(3):427-431.

[30] Choi S, Shah SP. Deformation measurement in concrete under compression using image correlation. Journal of experimental mechanics, 1997; 37(3):307-313.

[31] Corr D, Accardi M, Brady L, Shah S. Digital image correlation analysis of interfacial debonding properties and fracture behavior in concrete. Engineering fracture mechanics, 2007; 74:109-121.

[32] Helm JD, McNeill SR, Sutton MA. Improved three-dimensional image correlation for surface displacement measurement. OPT. ENG., 1996; 35(7):1911-1920.

[33] Choi HS, Cheunga JH, Kimb SH, Ahn JH. Structural dynamic displacement vision system using digital image processing. NDT\&E international, 2011; 44:597-608.

[34] Lee JJ, Shinozuka M. Real-time displacement measurement of a flexible bridge using digital image processing techniques. Experimental mechanics, 2006; 46:105-114.

[35] Hamid AA, Bolhassani M, Turner A, Minaei E, Moon FL. Mechanical properties of ungrouted and grouted concrete masonry assemblages. $12^{\text {th }}$ Canadian Masonry Symposium, Vancouver, British Columbia; 2013.

[36] Bolhassani M, Hamid AA, Lau AC, Moon F. Simplified micro modeling of partially grouted masonry assemblages. Construction and Building Materials, 2015;83:159-173.

[37] Masonry Standards Joint Committee (MSJC). Building code requirements for masonry structures. TMS 402-08, ACI 530-08, and ASCE 5-08, The Masonry Institute, Boulder, American Concrete Institute, ASCE, Farmington Hills, MI, Reston, VA, 2013.

[38] Ghanem GM, Salama AE, Elmagd SA, Hamid AA. Effect of axial compression on the behavior of partially reinforced masonry shear walls. Proc., 6th North American Masonry Conf. (NAMC), Philadelphia, 1993, 1145-1157.

[39] Ingham JM, Davidson B, Brammer D, Voon KC. Testing and codification of partially groutfilled nominally-reinforced concrete masonry subjected to in-plane cyclic loads. The Masonry Society Journal, 2001;19(1): 83-96. 
[40] Voon KC, Ingham JM. Experimental in-plane shear strength investigation of reinforced concrete masonry walls. Journal of Structural Engineering, 2006;132(3):400-408.

[41] Shing PB, Cao L. (1997) Analysis of partially grouted masonry shear walls. Gaitherburg (MD): US Department of Commerce. National Institute of Standards and Technology. NISTIR GCR 97-710.

[42] Minaie E, Mota M, Moon FL, Hamid AA. In-plane behavior of partially grouted reinforced concrete masonry shear walls. Journal of Structural Engineering, 2010;136(9):1089-1097. 